\title{
Primary Indicators of Critical Illness in Coronavirus Disease-2019
}

\author{
HOUSSAM ELDIN H. ABD ELNABY, M.D.1; MOSTAFA A.R. HUSSEIN, M.D.2; \\ MOHAMMAD A.A. AMIN, M.D. ${ }^{3}$ and MOHAMMAD E. ABO-GHABSHA, M.D. 4 \\ The Departments of Chest Diseases ${ }^{1}$, Internal Medicine ${ }^{2}$, Radiodiagnosis ${ }^{3}$ and Clinical Pathology ${ }^{4}$, Faculty of Medicine, \\ Al-Azhar University, Cairo, Egypt
}

\begin{abstract}
Background: Many studies discussed numerous predictors of severity in Coronavirus disease-2019 (COVID-19) patients. However, very limited number of these studies concerned with finding indicators of disease progression, ICU admission and life-threatening complications in such patients.

Aim of Study: To determine some of the baseline indicators that lead COVID-19 patients to develop the critically ill form of the disease.

Patients and Methods: This cross sectional study was conducted during the period from January 2021 to March 2021. It included 40 patients with COVID-19 infection, proved by positive reverse trascriptase real-time PCR (rt RT-PCR) admitted to Al-Hussein and Bab Al-Sha'reia University Hospitals (quarantine sectors). Studied patients were divided into two equal groups, based on the classification of the Chinese Centers of Disease Control and Prevention (CDC): (1) Severe (non-critically ill) group and (2) Critically ill group. Demographic data and co-morbidities of all participants were recorded and BMI was calculated. Baseline CBC, AST, ALT, ESR, CRP, ferritin, D-dimer and HRCT chest were done for all patients.
\end{abstract}

Results: Age, sex, BMI, smoking habit, CBC indices, ALT, AST and CRP did not show significant differences between severe and critically ill groups. However, ESR, Ddimer, ferritin, HRCT chest score, hypertension and diabetes mellitus showed statistically significant assosciation with the critically ill patients ( $p$-value $<0.05)$. HRCT chest score and hypertension were proved to be independent variables significantly associated with critical illness, unlike ESR which is a dependent variable. Hypertensive patients were 40 times more likely to be critically ill compared to non-hypertensive COVID-19 patients (adjusted OR=40.238). Additionally, for every increase in HRCT chest score by one point, the odds of being critically ill among COVID-19 patients increased twice (adjusted $\mathrm{OR}=2.1$ ).

Conclusion: Hypertension and diabetes mellitus increase the risk of developing critical illness in COVID-19 patients. Elevated ESR, D-dimer, ferritin levels and the more the percentage of HRCT chest involvement are associated with critical illness as well.

Correspondence to: Dr. Houssam Eldin H. Abd Elnaby, E-Mail: drhoussam151979@gmail.com
Key Words: Indicators - Critical illness - Coronavirus disease2019.

\section{Introduction}

ON the $11^{\text {th }}$ of March 2020, the WHO announced COVID-19 as a pandemic infectious disease. Since then, all practice, knowledge and attitudes have been continuously developed for the COVID-19 siege [1].

The common clinical symptoms of patients with COVID-19 are fever, cough, dyspnea and fatigue, which are similar to those of severe acute respiratory syndrome coronavirus (SARS-CoV) and Middle East respiratory syndrome coronavirus (MERS-CoV) [2].

According to the criteria provided by the Chinese CDC, COVID-19 severity is classified to: (1) Mild to moderate disease: Including non-pneumonia or mild pneumonia (mild symptoms without dyspnea, respiratory frequency $<30 / \mathrm{min}$, blood oxygen saturation $\left(\mathrm{SO}_{2}\right)>93 \%$ and $\mathrm{PaO}_{2} / \mathrm{FiO}_{2}$ ratio $\geq 300 \mathrm{mmHg}$ ), (2) Severe disease: Including dyspnea, respiratory frequency $\geq 30 / \mathrm{min}, \mathrm{SO}_{2} \leq 93 \%$, $\mathrm{PaO}_{2} / \mathrm{FiO}_{2}$ ratio $<300 \mathrm{mmHg}$ or lung infiltrates $>50 \%$ within 24 to $48 \mathrm{~h}$ and (3) Critical disease: Including acute respiratory distress syndrome (ARDS), respiratory failure, septic shock or multiple organ dysfunction (MOD)/failure (MOF) [3].

Several comorbidities, including chronic respiratory disease, cardiovascular disease, diabetes mellitus and hypertension were observed more frequently among patients with severe COVID-19 than with the mild ones. Lower levels of lymphocytes and hemoglobin; elevated levels of leukocytes, aspartate aminotransferase (AST), alanine aminotransferase (ALT), blood creatinine, blood urea nitrogen, high-sensitivity troponin, creatine kinase, high sensitivity $\mathrm{C}$-reactive protein, inter- 
leukin 6, D-dimer, ferritin, lactate dehydrogenase $(\mathrm{LDH})$, and procalcitonin (PCT); and a high erythrocyte sedimentation rate (ESR) were also associated with severe COVID-19 [4].

Aim of the work:

The aim of this study is to determine some of the baseline indicators that lead COVID-19 patients to develop the critically ill form of the disease.

\section{Patients and Methods}

This cross sectional study was conducted during the period from January 2021 to March 2021. It included 40 patients with COVID 19 infection, proved by positive reverse trascriptase real-time PCR (rt RT-PCR) of their upper respiratory swabs, admitted to Al-Hussein and Bab Al-Sha'reia University Hospitals (quarantine sectors).

Studied patients were divided into two equal groups, each of which included 20 patients, based on the classification of the Chinese (CDC). The two groups were: (1) Severe (non-critically ill) group, managed in the intermediate care unit and (2) Critically ill group, managed in the intensive care unit (ICU).

Patients with old pulmonary fixed lesions on their chest radiographs, those known to have any type of diffuse parenchymal lung diseases, those with hematological diseases or other conditions that affect normal counts or percentages of complete blood count, those known to have elevated liver enzymes, those with conditions alternate with Ddimer levels, e.g. renal impairment, sepsis, pregnancy, ... etc, those with active tuberculosis infection, immunological disorders or current malignancies or those with any other causes of sustained elevation of the inflammatory biomarkers were totally excluded from the study.

Ethical clearance was granted by Al-Azhar Faculty of Medicine Ethics and Research Committee. Informed consents were obtained from all patients or their first degree relatives.

All subjects were submitted to the following; full history taking, thorough clinical examination, baseline labs including: Complete blood count, random blood sugar, AST, ALT and inflammatory biomarkers (ESR, CRP, D-dimer and ferritin) and chest high resolution computed tomography (HRCT) without IV contrast.

\section{Data collection:}

Demographic data of all studied patients were recorded, including age, sex, residence, occupation, nationality, smoking habit and body mass index
(BMI). Smoking index was expressed in pack/year, while BMI was calculated by dividing the weight in kilograms over the squared height in meters. Laboratory results and co-morbidities (hypertension and diabetes mellitus) were recorded as well.

\section{Chest CT evaluation:}

A semi-quantitative method was used to estimate pulmonary involvement by major radiological patterns associated with COVID-19 pneumonia, i.e. ground glass opacities (GGOs), crazy-paving pattern and consolidation.

Each of the 5 lung lobes was visually scored from 0 to 5 as follows: $0=$ no involvement, $1=<5 \%$ involvement, $2=5 \%-25 \%$ involvement, $3=26 \%$ $49 \%$ involvement, $4=50 \%-75 \%$ involvement and $5=>75 \%$ involvement. The total HRCT chest score was the sum of the individual lobar scores and ranged from 0 (no involvement) to 25 (maximum involvement) [5].

Images were taken using (Toshiba Aquilion 64 CT Scanner, Toshiba Medical Systems Corporation, Shimoishigami St, Otawara City, Tochigi, Japan). All CT images were independently reviewed and scored by two chest radiologists with more than 10 years of experience, blinded to the clinical data and laboratory indicators.

\section{Statistical analysis:}

Statistical analysis of data was performed using Statistical Package for the Social Sciences (SPSS) version 15 (IBM corp., Chicago, IL, USA). Quantitative variables were expressed as mean \pm SD (standard deviation) and tested using independent sample $t$-test. Qualitative variables were expressed as frequencies (percentages) and tested using Chisquare test. $p$-value at the level of significance was $\leq 0.05$. Logistic regression analysis was used to examine the association of independent variable(s) with one dichotomous dependent variable, while discriminant analysis was used to interpret the predictive equation for better understanding of the relations that may exist among the variables.

\section{Results}

As shown in (Table 1), age was insignificantly higher in the critically ill patients than in the severe patients. Moreover, CBCs indices, ALT, AST and BMI did not show significant differences between the two groups. Inflammatory markers including ESR, D-dimer and ferritin and HRCT chest score were significantly higher in patients presented with critical illness compared to the others ( $p$-value $<0.05)$. However, CRP did not differ between the study groups. 
Table (1): Distribution of quantitative variables between studied groups.

\begin{tabular}{lllll}
\hline $\begin{array}{l}\text { Demographic } \\
\text { factors }\end{array}$ & \multicolumn{1}{c}{$\begin{array}{c}\text { Severe } \\
\mathrm{N}=20\end{array}$} & $\begin{array}{c}\text { Critically ill } \\
\mathrm{N}=20\end{array}$ & $\begin{array}{l}t \text {-test } \\
\text { value }\end{array}$ & $\begin{array}{c}p \text { - } \\
\text { value }\end{array}$ \\
\hline Age & $51.9 \pm 13.4$ & $56.8 \pm 14.2$ & -1.12 & 0.27 \\
BMI & $31.1 \pm 4.4$ & $33.8 \pm 7.4$ & -1.4 & 0.17 \\
WBCs & $10.2 \pm 5$ & $11.8 \pm 7.3$ & -0.8 & 0.43 \\
Neutrophils & $8.8 \pm 4.7$ & $10.2 \pm 6.9$ & -0.74 & 0.46 \\
$\quad$ count & & & & \\
Neutrophils \% & $83.6 \pm 7.96$ & $83.3 \pm 8.2$ & 0.13 & 0.9 \\
Lymphocytes & $0.88 \pm 0.46$ & $1.08 \pm 0.81$ & -0.96 & 0.34 \\
$\quad$ count & & & & \\
Lymphocytes \% & $10.4 \pm 6.8$ & $10.8 \pm 6.5$ & 0.18 & 0.86 \\
Hemoglobin & $12.7 \pm 2.6$ & $11.9 \pm 2.6$ & 0.93 & 0.36 \\
Platelets count & $214 \pm 65.5$ & $230 \pm 78.6$ & -0.7 & 0.49 \\
ALT & $56.3 \pm 49.5$ & $67.9 \pm 48.2$ & -0.75 & 0.46 \\
AST & $72.9 \pm 70$ & $101.7 \pm 73$ & -1.27 & 0.21 \\
ESR & $62.9 \pm 19.6$ & $83.1 \pm 29.8$ & -2.53 & $0.016^{*}$ \\
CRP & $122.1 \pm 89.3$ & $159.2 \pm 81.2$ & -1.37 & 0.18 \\
D-dimer & $0.6 \pm 0.4$ & $1.04 \pm 0.8$ & -2.16 & $0.039^{*}$ \\
Ferritin & $1070 \pm 1048$ & $1987 \pm 1751$ & -2.00 & $0.05^{*}$ \\
HRCT chest score & $12.9 \pm 3$ & $18.25 \pm 2.4$ & -6.2 & $0.00^{*}$ \\
\hline
\end{tabular}

$* p$-value at the level of significance $\leq 0.05$.

BMI : Body mass index.

WBCs : White blood cells.

ALT : Alanine transaminase.

AST : Aspartate transaminase.

ESR : Erythrocyte sedimentation rate.

CRP : C-reactive protein.

HRCT : High resolution computed tomography.

As shown in (Table 2), there were no significant differences between the two studied groups as regard sex and smoking habit. The critically ill group had significant positive associations with hypertension and diabetes mellitus ( $p$-value $=0.008$ and 0.04 respectively) compared to the severe group.

Table (2): Distribution of qualitative variables between studied groups.

\begin{tabular}{|c|c|c|c|c|c|}
\hline $\begin{array}{l}\text { Medical } \\
\text { history }\end{array}$ & $\begin{array}{c}\text { Severe } \\
\mathrm{N}=20 \\
(\%)\end{array}$ & $\begin{array}{c}\text { Critically } \\
\text { ill } \\
\mathrm{N}=20 \\
(\%)\end{array}$ & $\begin{array}{c}\text { Total } \\
\text { Number }\end{array}$ & $\begin{array}{c}\chi^{2} \\
\text { value }\end{array}$ & $\begin{array}{c}p- \\
\text { value }\end{array}$ \\
\hline \multicolumn{6}{|l|}{ Sex: } \\
\hline Male & $14(70)$ & $15(75)$ & 29 & \multirow[t]{2}{*}{0.13} & \multirow[t]{2}{*}{0.72} \\
\hline Female & $6(30)$ & $5(35)$ & 11 & & \\
\hline \multicolumn{6}{|l|}{ Smoking: } \\
\hline No & $15(75)$ & $13(65)$ & 28 & \multirow[t]{2}{*}{0.48} & \multirow[t]{2}{*}{0.49} \\
\hline Yes & $5(25)$ & $7(35)$ & 12 & & \\
\hline \multicolumn{6}{|c|}{ Hypertension: } \\
\hline No & $17(85)$ & $9(45)$ & 26 & \multirow[t]{2}{*}{7.03} & \multirow[t]{2}{*}{$0.008 *$} \\
\hline Yes & $3(15)$ & $11(55)$ & 14 & & \\
\hline \multicolumn{6}{|l|}{ Diabetes } \\
\hline \multicolumn{6}{|l|}{ Mellitus: } \\
\hline No & $17(85)$ & $9(45)$ & 27 & \multirow[t]{2}{*}{4.28} & \multirow[t]{2}{*}{$0.04 *$} \\
\hline Yes & $3(15)$ & $11(55)$ & 13 & & \\
\hline
\end{tabular}

Using logistic regression analysis in (Table 3), HRCT chest score and hypertension were proved to be independent variables significantly associated with critical illness, unlike ESR which is a dependent variable. In binary logistic regression model, the $\log \mathrm{p} / 1-\mathrm{p}=-15.424+3.695 \mathrm{HTN}+0.742$ HRCT score $+0.038 \mathrm{ESR}$, where $(p)$ is the probability to be critically ill among severe Covid-19 patients. The effects of HRCT chest score and hypertension were significant ( $p$-value $<0.05$ ). It was concluded that the hypertensive patients were 40 times more likely to be critically ill compared to nonhypertensive COVID-19 patients [(adjusted odd ratio $(\mathrm{aOR})=40.238]$. Additionally, for every increase in HRCT chest score by one point, the odds of being critically ill among COVID-19 patients increased twice $(\mathrm{aOR}=2.1)$. The model shows good prediction of $87.5 \%$ and $\mathrm{R}^{2}=81.6 \%$.

The addition of D-dimer, ferritin and CRP to the model decreases its predictability indicated by ROC curve, $\mathrm{R}^{2}$, Omnibus test and classification plots.

Table (3): Determination of possible predictors of critical illness among severe COVID-19 patients using logistic regression.

\begin{tabular}{lccccc}
\hline $\begin{array}{l}\text { Independent } \\
\text { Variables }\end{array}$ & $\begin{array}{c}\text { Regression } \\
\text { coefficient } \\
\text { (B) }\end{array}$ & $\begin{array}{c}\text { Standard } \\
\text { error }\end{array}$ & $\begin{array}{c}\text { Test } \\
\text { value }\end{array}$ & aOR & $\begin{array}{c}p \text { - } \\
\text { value }\end{array}$ \\
\hline ESR & 0.038 & 0.028 & 1.843 & 1.039 & 0.175 \\
$\begin{array}{l}\text { HRCT chest } \\
\quad \text { score }\end{array}$ & 0.742 & 0.259 & 8.236 & 2.100 & $0.004^{*}$ \\
HTN & 3.695 & 1.852 & 3.979 & 40.238 & $0.046^{*}$ \\
Constant & -15.424 & 4.806 & 10.301 & 0.000 & $0.001^{*}$ \\
\hline
\end{tabular}

$* p$-value at the level of significance $\leq 0.05$.

aOR : Adjusted odd ratio.

ESR : Erythrocyte sedimentation rate.

HRCT : High resolution computed tomography.

HTN : Hypertension.

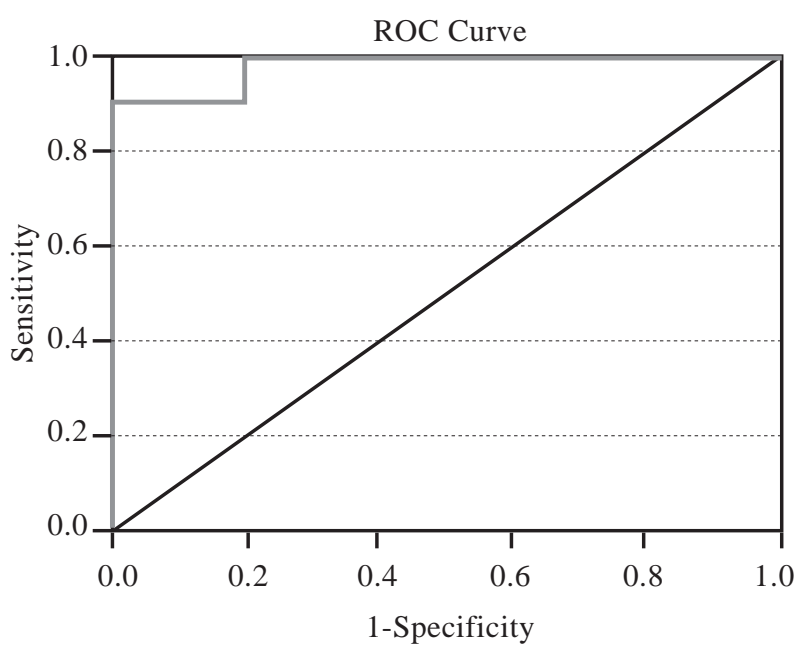

Fig. (1): ROC curve of the logistic regression model. 
As shown in (Table 4), when using discriminant analysis (without HRCT chest score), the crossvalidated grouped cases correctly classified is $70 \%$ which is greater than the proportional by chance accuracy rate that equal $62.5 \%$. (sensitivity $=65 \%$ and specificity $=85 \%$ ).

Discriminant score $=-2.559+0.022(\mathrm{ESR})+$ 0.497 (D-dimer) +0.00035 (ferritin) .

Score above zero is considered critically ill, while negative score will be classified as noncritically ill based on centroids of critical and noncritical illness $=0.493$ and -0.493 respectively.

Addition of HRCT chest score increased the cross-validated grouped cases correctly classified to $80 \%$ (sensitivity $=90 \%$ and specificity $=80 \%$ ).

Discriminant score $=-6.853+0.019(\mathrm{ESR})-$ 0.268 (D-dimer) +0.000137 (ferritin) +0.346 (HRCT chest score).

Table (4): Determination of possible predictors of critical illness among severe COVID-19 patients using discriminant analysis (without HRCT score).

\begin{tabular}{lcccc}
\hline Predictors & $\begin{array}{c}\text { Structure } \\
\text { matrix }\end{array}$ & $\begin{array}{c}\text { Wilks' } \\
\text { Lambda }\end{array}$ & $\begin{array}{c}\text { F- } \\
\text { value }\end{array}$ & $\begin{array}{c}p \text { - } \\
\text { value }\end{array}$ \\
\hline ESR & 0.81 & 0.86 & 6.4 & $0.016^{*}$ \\
D-dimer & 0.69 & 0.89 & 4.7 & $0.037^{*}$ \\
Serum ferritin & 0.64 & 0.9 & 4.0 & $0.05^{*}$ \\
Discriminant function & - & 0.8 & $8.3 ¥$ & 0.04 \\
\hline
\end{tabular}

* $p$-value at the level of significance $\leq 0.05$.

$¥$ : Chi-square value.

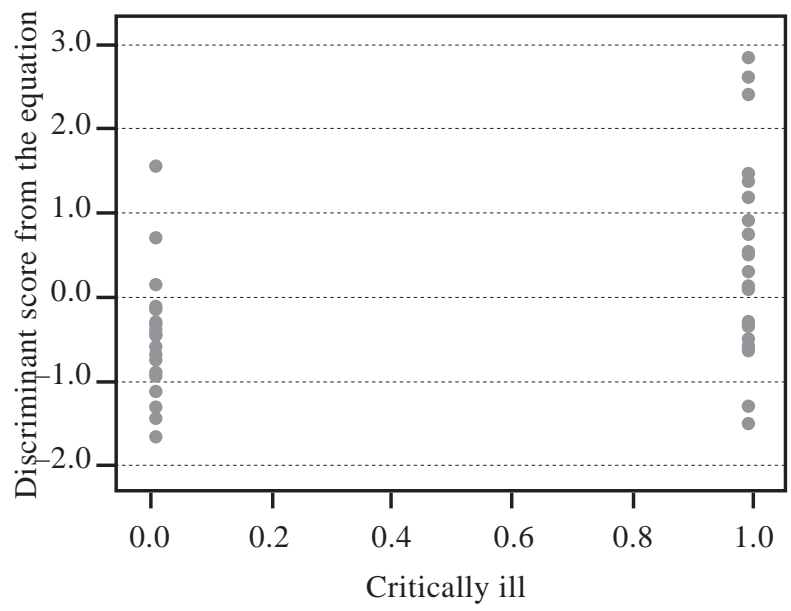

Fig. (2): The relationship between critical illness and discriminant score obtained from the equation (without HRCT score); negative score indicates non-critical $(\mathrm{X}$-axis $=0)$ and positive score indicates critical status $(\mathrm{X}$-axis $=1)$.

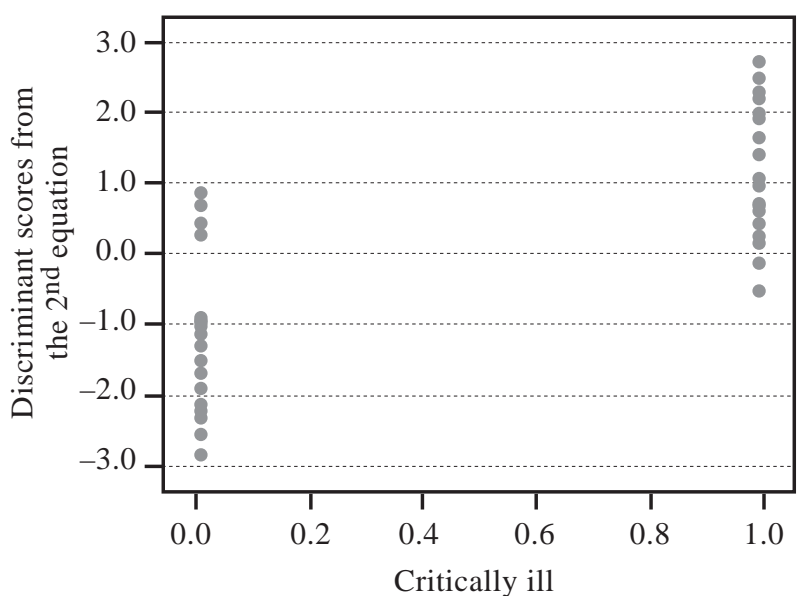

Fig. (3): The relationship between critical illness and discriminant score obtained from the equation (with HRCT score); negative score indicates non-critical (X-axis $=0)$ and positive score indicates critical status (Xaxis $=1$ ).

\section{Discussion}

Although being based on a small sample size and with significant heterogeneity between studies, the findings of some systematic literature search and pooled analysis, suggest that severe COVID19 cases are associated with prominent elevations of ESR as compared to non-severe cases, reflecting the more profound inflammatory response and expression of acute-phase proteins. Initial Chinese reports at the beginning of COVID-19 era named ESR as the most sensitive biomarker related to ICU admission and disease progression, but these reports carried prominent scientific bias [6].

Merging with our results, an Italian study with 141 COVID-19 patients, proved that patients who needed ICU admission had 5.8 times higher serum ferritin compared with those with mild disease. Serum ferritin levels were positively correlated with the disease severity in both male and female patients, and when disaggregating data by sex, the only parameter that showed a significant difference between males and females was ferritin, denoting its independence in assessing COVID-19 severity and ICU need [7].

The current findings matched with those of a meta-analysis of 13 studies, which reported that D-dimer was increased and significantly higher in COVID-19 patients with severe disease or a composite end-point compared with non-severe disease, in ARDS compared with non-ARDS patients and in deceased ARDS patients compared with ARDS patients who survived (all $p<0.001$ ) [8].

As well, an Indian study concluded that COVID-19 infected patients with elevated D-dimer 
levels had worse clinical outcomes (mortality, ICU admission or ARDS), and thus measurement of Ddimer can guide in clinical decision making [9].

Our results coincide with those of a study including 189 patients, in which patients were divided into critically ill and non-critically ill according to $\mathrm{PaO}_{2} / \mathrm{FIO}_{2}$ ratio and oxygen saturation $\left(\mathrm{SaO}_{2}\right)$. This result found that, lung volume involvement was significantly higher in critically ill vs. noncritically ill patients $(38.5 \%$ vs. $5.8 \%, p<0.05)$. A cut-off of $23.0 \%$ of lung involvement showed $96 \%$ sensitivity and $96 \%$ specificity in distinguishing critically ill patients from patients with less severe disease, concluding that quantitative $\mathrm{CT}$ assessment of lung disease, has a significant relationship with clinical severity and may predict the need for invasive ventilation in patients with COVID-19 [10].

In the same line, Ruch and co-workers reported that, the extent of lesions on initial CT was independently associated with prognosis $(\mathrm{aOR}=2.35$, 95\% confidence interval 1.24-4.46; $p<0.01)$. Most patients with lung involvement $>50 \%(69.5 \%)$ developed severe disease compared to patients with lung involvement of $26-50 \%(40.9 \%)$ and $25 \%(22.9 \%)(p<0.01$ in both), while none of the patients with normal CT developed severe disease [11].

Unlike our findings, Kim and his colleagues reported age $>50$ years, male sex and obesity as independent factors associated with ICU admission in COVID-19 patients [12]. Alkhatib et al., found that patients admitted to the ICU were older (62 vs. 55 years, $p=0.003)$ and had higher BMI (36.5 $\left.\mathrm{kg} / \mathrm{m}^{2} \mathrm{vs} .31 .9 \mathrm{~kg} / \mathrm{m}^{2}, p=0.002\right)$. In unadjusted and adjusted analysis, the factors most associated with ICU admission in their study were age (aOR: 1.073; 95\% CI: 1.033-1.114), BMI (aOR: 1.115; 95\% CI: 1.052-1.182) and lung disease (aOR: $3.097 ; 95 \%$ CI: 1.137-8.437) [13].

Our findings correspond to those of a large meta-analysis of 30 studies with a total of 6452 patients, which revealed that DM was associated with severe COVID-19 (RR 2.45 [1.79, 3.35], $p<0.001$; I2: 45\%), ARDS (RR 4.64 [1.86, 11.58], $p=0.001 ; \mathrm{I} 2: 9 \%)$, and disease progression (RR $3.31[1.08,10.14], p=0.04$; I2: 0\%). Metaregression showed that the association with composite poor outcome was influenced by age $<55$ years $(p=0.003)$ and hypertension $(p<0.001)$ [14].

Many evidences demonstrate that diabetes is a risk factor for disease progression towards critical illness, development of acute respiratory distress syndrome, admission to intensive care unit, need for mechanical ventilation and ultimately death. The mechanisms underlying the relationship between COVID-19 and diabetes remain to be elucidated. It is still unclear whether this poor outcome is related to diabetes per se, especially if poorly controlled or referred to the various comorbidities/complications associating diabetes that predispose patients with COVID-19 to a worse prognosis [15]. Hyperglycemia is an independent factor associated with severe prognosis in people hospitalized due to COVID-19 [16].

In agreement with us, a large study included 1099 patients, found that hypertension was a more prevalent condition in those who lead the primary composite end-point (admission to ICU, the use of mechanical ventilation or death; $35.8 \%$ versus $13.7 \%)$ and in those with severe disease $(23.7 \%$ versus $13.4 \%$ ) [17].

Likewise to our results, a meta-analysis included 19 studies of 15,302 patients, among whom $38.2 \%$ were hypertensive showed that hypertension was significantly associated with the increased risk of adverse outcomes in COVID-19 patients on the basis of the adjusted effect estimates, which suggests that hypertension is an independent risk factor for predicting the severity and mortality of COVID19 patients. Thus, COVID-19 patients with hypertension deserve more clinical attention [18].

Parveen and his colleagues, reported that diabetes prevalence was lower in the survivors (OR: 0.56; 95\% CI: $0.35-0.90 ; p=0.017$; I2: $0.0 \%)$ and non-severe (OR: 1.66; 95\%CI: 1.20-2.30; $p=0.002$; I2: $0.0 \%$ ) patients when compared with nonsurvivors and severe patients. Hypertension was positively associated with ICU care (OR: 0.42; 95\% CI: $0.22-0.81 ; p=0.009 ; \mathrm{I} 2: 0.0 \%)$ and severity (OR: 2.69; 95\%CI: $1.27-5.73 ; p=0.01 ; \mathrm{I} 2: 52.4 \%$ ) [19].

A meta-analysis of 310 patients, including 113 patients with hypertension and 197 patients without hypertension, found that patients with hypertension were more likely to be transferred to the intensive care unit compared to non-hypertensive patients. The neutrophil count, LDH, fibrinogen and Ddimer levels in hypertensive patients were significantly higher than those in non-hypertensive patients $(p<0.05)$. However, multivariate analysis (adjusted for age and sex) failed to show that hypertension was an independent risk factor for COVID-19 mortality or severity [20].

In contrary to our results, Zhao and co-workers found no association between comorbidities and 
ICU admission [21]. Another study concluded that diabetes was not associated with the need for ICU care [19].

\section{Conclusion:}

Hypertension and diabetes mellitus increase the risk of developing critical illness in COVID19 patients. Elevated ESR, D-dimer, ferritin levels and the more the percentage of HRCT chest involvement are associated with critical illness as well. Further studies with larger numbers of patients are required.

\section{References}

1- ALZOUBI H., ALNAWAISEH N., AL-MNAYYIS A., ABU-LUBADA M., AQEL A. and AL-SHAGAHIN H.: COVID-19 knowledge, attitude and practice among medical and non-medical university students in Jordan. J. Pure Appl. Microbiol., 14 (1): 17-24, 2020.

2- HUANG C., WANG Y., LI X., REN L., ZHAO J. and HU Y.: Clinical features of patients infected with 2019 novel coronavirus in Wuhan, China. Lancet, pii: S0140-6736 (20): 30183-30185, 2020.

3- WU Z. and MCGOOGAN J.M.: Characteristics of and important lessons from the coronavirus disease 2019 (COVID-19) outbreak in China: Summary of a report of 72314 cases from the Chinese Center for Disease Control and Prevention. JAMA, 323: 1239-1242, 2020.

4- MUDATSIR M., FAJAR J.K., WULANDARI L., SOEGIARTO G. and ILMAWAN M.: Predictors of COVID19 severity: A systematic review and meta-analysis. F1000 Research, 9: 1107, 2020.

5- PAN F., YE T., SUN P., GUI S., LIANG B., LI L., ZHENG D., WANG J., HESKETH R.L., YANG L. and ZHENG C.: Time course of lung changes on chest CT during recovery from 2019 novel Coronavirus (COVID-19) pneumonia. Radiology, 295 (3): 715-721, 2020.

6- HENRY B.M., DE OLIVEIRA M.H., BENOIT S., PLEBANI M. and LIPPI G.: Hematologic, biochemical and immune biomarker abnormalities associated with severe illness and mortality in coronavirus disease 2019 (COVID19): A meta-analysis. Clin. Chem. Lab. Med., 58: 10211028,2020

7- GANDINI O., CRINITI A., GAGLIARDI M.C., BALLESIO L., GIGLIO S., BALENA A., CAPUTI A., ANGELONI A. and LUBRANO C.: Sex-disaggregated data confirm serum ferritin as an independent predictor of disease severity both in male and female COVID-19 patients. J. Infect., 82 (3): 414-451, 2021.

8- VIDALI S., MOROSETTI D., COSSU E., LUISI M.L.E., PANCANI S., SEMERARO V. and CONSALES G.: Ddimer as an indicator of prognosis in SARS-CoV-2 infection: a systematic review. ERJ Open Res., 6: 00260, 2020.

9- BANSAL A., SINGH A.D., JAIN V., AGGARWAL M., GUPTA S. and PADAPPAYIL R.P.: The association of D-dimers with mortality, intensive care unit admission or acute respiratory distress syndrome in patients hospitalized with coronavirus disease 2019 (COVID-19): A systematic review and meta-analysis. Heart \& Lung, 000: $1-4,2020$.
10- LEONARDIA A., SCIPIONEA R., ALFIERIA G., PETRILLOA R., DOLCIAMIA M. and CICCARELLIA F.: Role of computed tomography in predicting critical disease in patients with covid-19 pneumonia: A retrospective study using a semiautomatic quantitative method. Eur. J. Radiology, 130: 109202, 2020.

11- RUCH Y., KAEUFFER C., OHANA M., LABANI A., FABACHER T. and BILBAULT P.: CT lung lesions as predictors of early death or ICU admission in COVID19 patients. Clin. Microbiol. Infect., 26: 14717e5-1417e8, 2020.

12- KIM L., GARG S., O'HALLORAN A., WHITAKER M., PHAM H. and ANDERSON E.J.: Risk Factors for Intensive Care Unit Admission and In-hospital Mortality Among Hospitalized Adults Identified through the US Coronavirus Disease 2019 (COVID-19)-Associated Hospitalization Surveillance Network (COVID-NET). Clin. Infect. Dis., 1012: 1-9, 2020.

13- ALKHATIB A.L., KRENISKE J., ZIFODYA J.S., FONSECA V. and TAHBOUB M.: BMI is associated with Coronavirus disease 2019 intensive care unit admission in African Americans. Obesity, 28 (10): 1798-1801, 2020.

14- HUANG I., LIM M.A. and PRANATA R.: Diabetes mellitus is associated with increased mortality and severity of disease in COVID-19 pneumonia e A systematic review, meta-analysis, and meta-regression. Diabetes Metab. syndr., 14 (4): 395-403, 2020.

15- PUGLIESE G., VITALE M., RESI V. and ORSI E.: Is diabetes mellitus a risk factor for Coronavirus disease 19 (COVID 19)? Acta. Diabetologica., 57 (11): 1275-1285, 2020.

16- COPPELli A., GIANNARELli R., ARAGONA M., PENNO G. and FALCONE M.: Hyperglycemia at hospital admission Is associated with severity of the prognosis in patients hospitalized for COVID-19: The Pisa COVID19 Study. Diabetes Care., 43: 2345-2348, 2020.

17- GUAN W.J., NI Z.Y. and HU Y.: Clinical characteristics of coronavirus disease 2019 in China. N. Engl. J. Med., 382: $1708-1720,2020$

18- WANG D., YIN Y., HU C., LIU X., ZHANG X. and ZHOU S.: Clinical course and outcome of 107 patients infected with the novel coronavirus, SARS-CoV-2, discharged from two hospitals in Wuhan, China. Crit. Care., 24 (1): 188, 2020.

19- PARVEEN R., SEHAR N., BAJPAI R. and AGARWAL N.B.: Association of diabetes and hypertension with disease severity in covid-19 patients: A systematic literature review and exploratory meta-analysis. Diabetes Res. Clin. Pract., 166: 108295, 2020.

20- HUANG S., WANG J., LIU F., LIU J., CAO G., YANG C., LIU W., TU C., ZHU M. and XIONG B.: COVID-19 patients with hypertension have more severe disease: A multicenter retrospective observational study. Hypertension Research, 43: 824-831, 2020.

21- ZHAO Z., CHEN A., HOU W. , GRAHAM J.M. , LI H., RICHMAN P.S., THODE H.C., SINGER A.J. and DUONG T.Q.: Prediction model and risk scores of ICU admission and mortality in COVID-19. PLOS One., 15 (7): $\mathrm{e} 0236618,2020$ 


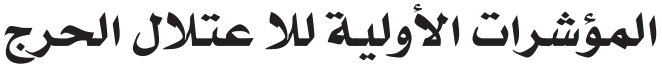

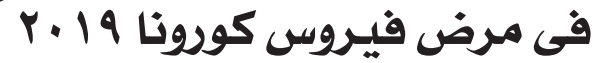

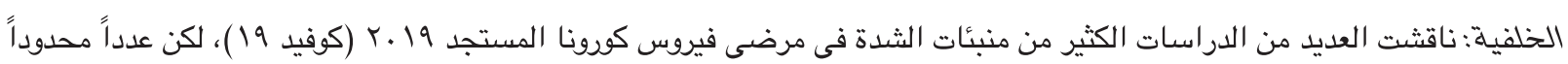

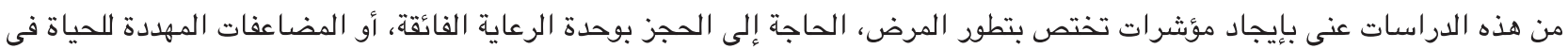
هؤلاء المرضى.

الهدف من الدراسة: تحديد بعض المؤشرات القاعدية التى تقود مرضى (كففيد 19) لتجاوز مرحلة الشدة إلى طريق الاعتلال الحرج.

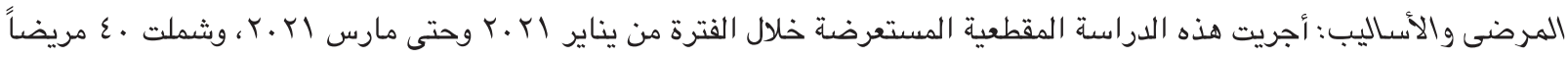

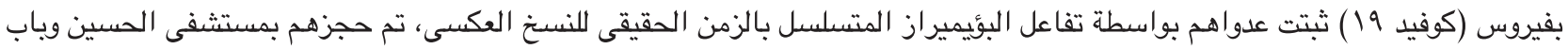

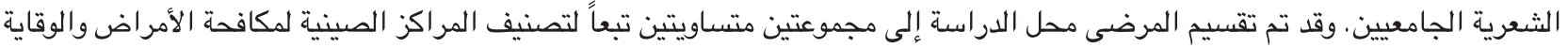

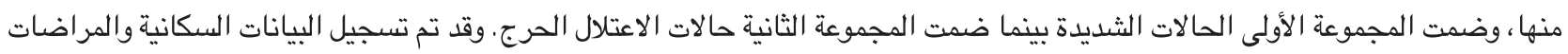

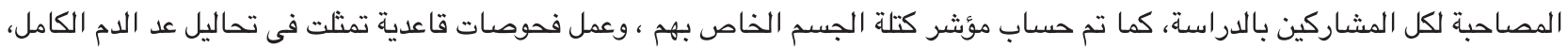

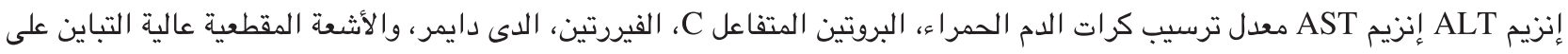

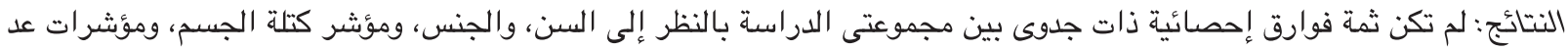

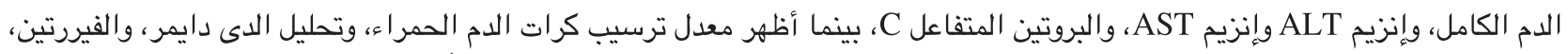

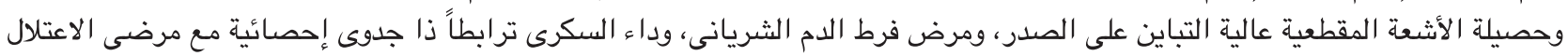

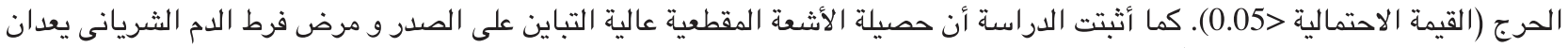

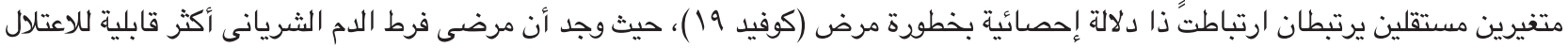

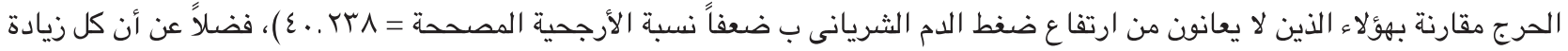

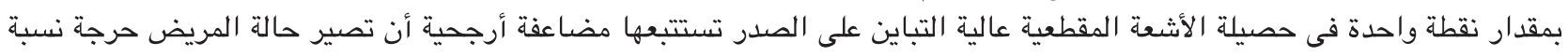

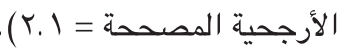

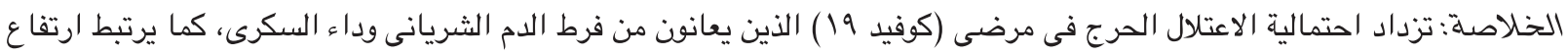

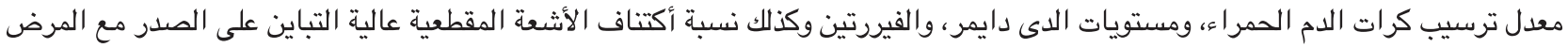

